\title{
ZUM VORČAKA-HORIZONT IN DER SÜDWESTSLOWAKEI
}

\author{
Zoja Benkovsky-Pivovarová
}

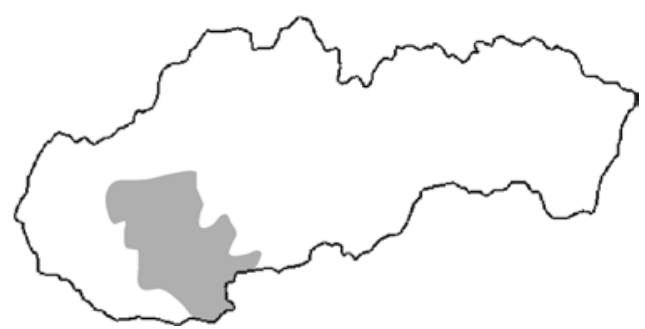

DOI: https://doi.org/10.31577/szausav.2019.65.1

Key words: southwestern Slovakia, Middle-Danube Tumulus culture, Carpathian Tumuli culture, Proto-Čaka horizon, Čaka culture, Velatice culture

\section{On the Proto-Čaka Horizon in Southwestern Slovakia}

The article deals with the concept of the Proto-Čaka horizon by J. Paulík from 1963 dated to the interface of stages BC/BD. Analysis of the sites of this horizon and typical shapes of pottery has proved that its existence cannot be confirmed on the basis of the finds published in 1963. Dating of this horizon has no support in the bronze industry and the pottery confirms not only surviving shapes of tumuli cultures until stages BD/HA1 but also distinct presence of the Velatice culture in the territory of the Čaka culture.

Dieser Beitrag befasst sich mit der Datierung des Vorčaka-Horizontes in der Südwestslowakei; sein unmittelbarer Anlass ist die Publikation des Gräberfeldes von St. Margarethen im Burgenland und die damit im Zusammenhang stehende Frage der kulturellen Zugehörigkeit der Hügelgräber der Stufen $\mathrm{BD} / \mathrm{HA} 1$ in Ostösterreich.

Den Terminus „Vorčaka-Horizont“ führte in die Literatur J. Paulík im Jahre 1960 ein; der Autor betrachtete ihn als eine Arbeitshypothese, die durch neue Grabungen zu bestätigen wäre (Paulík 1960, 414, 426 f.). Den Beginn dieses Horizontes setzte J. Paulík in die Stufe BC, seine Dauer wurde von J. Paulík und A. Točík auf den Übergang der Stufen BC/BD eingeschränkt (Paulík 1960, 426 f.; Točík/Paulík 1960, chronologische Tabelle auf S. 93). In der slowakischen Literatur begegnet man aber außer der Beibehaltung der ursprünglichen Datierung (z. B. Furmánek/Veliačik/Vladár 1991, 123; 1999, 80; Ožd’áni 2015, 169) auch den leicht abgewandelten Datierungen des Vorčaka-Horizontes in die Stufen BC-BD (Točík/Vladár 1971, 406), in die Stufe BD (Romsauer/Veliačik 1987, 296) und in die späte Hügelgräberzeit/frühe Urnenfelderzeit (Novotná 1980, Abb. 1; 1984, Abb. 1). Es wird eine Entwicklung der Caka-Kultur aus der Karpatenländischen Hügelgräberkultur angenommen (z. B. Furmánek 1981, 74; Furmánek/Veliačik 1980, 169; Furmánek/Veliačik/ Vladár 1991, 123; 1999, 80; Oždáni 2015, 169; Paulík 1963, 315; Točík 1964, 61; Točík/Vladár 1971, 406).

Im Jahre 1963 stellte J. Paulík eine Liste von Fundstellen der Čaka-Kultur zusammen, in der auch die des Vorčaka-Horizontes inkludiert waren (Paulík 1963, 294-306); sie ist die Ausgangsbasis dieses Beitrages. Da die von J. Paulík berücksichtigten Fundbestände nach wie vor unpubliziert sind, ist man gezwungen, sich mit der vor über 50 Jahren veröffentlichten Auswahl der Funde zu befassen. Es wird dabei die von J. Říhovský ausgearbeitete Periodisierung der älteren Phase der westlichen Gruppe der Mitteldonauländischen Urnenfelderkultur- der Velatice-Kultur - angewendet, d. h. es werden die Stufen Blučina (Benkovsky-Pivovarová 2015, 75; ohne Kopčany, s. dazu Šabatová 2006, 107 f.), Baierdorf-Lednice und Velatice-Očkov zitiert (Ǩ́hovský 1982, chronologische Tab. auf S. 91); weitere Termini sind in Klammern vor dem Namen des Autors angeführt. Eingangs ist darauf aufmerksam zu machen, dass J. Ř́hovský bereits im Jahre 1963 auf einige Gefäßformen und -elemente in der Čaka-Kultur aufmerksam machte, die der Velatice-Kultur Südmährens und Niederösterreichs nahe stehen; er zählte dazu Amphoren mit trichterförmigem Hals und Schüsseln mit eingezogenem Rand, hochgezogene, dachförmig gekantete Henkel, schräge und waagrechte Facettierung der Schulter der Gefäße, Randlappen und Hohlfüßchen unterschiedlicher Größe (Ríhovský 1963, 82).

Die Liste J. Paulíks setzt sich aus 80 Fundstellen der Čaka-Kultur zusammen. Von ihnen wurden 11 in einen zumindest teilweisen Zusammenhang mit dem Vorčaka-Horizont gebracht, und zwar Bešeňov, Branč, Dolné Otrokovce, Dražovce, Horné Semerovce, Horné Lefantovce, Mlynárce, Polný Kesov, Salka, 
Tekovský Hrádok und Topolčany. Da man sich bei der Zitierung des Vorčaka-Horizontes in der slowakischen Literatur immer auf einige dieser Fundstellen beruft (z. B. Furmánek 1981, 74; Furmánek/Veliačik/ Vladár 1991, 124; 1999, 80; Oždáni 2015, 169), werden die Angaben J. Paulíks zu den Fundstellen dieses Horizontes in einer Kurzform wiedergegeben. Für Behausungen wurde die slowakische Bezeichnung Hütte (chata) beibehalten.

\section{Bešeňov (Paulík 1963, Nr. 5)}

Siedlung; Funde aus einem Graben. Vorčaka-Horizont und Čaka-Kultur. Auswahl der Keramik (Paulík 1963, Abb. 12). Auf der Abbildung bei J. Paulík (1963, Abb. 40: F16) eine Amphore des Vorčaka-Horizontes.

Anm. d. Verf.: Nach der Abb. 157 bei J. Paulík (1960) stammen die Funde (Paulík 1963, Abb. 12: 3-11) aus Kulturschichten und die Funde (Paulík 1960, Abb. 157: 12-17) aus der Grube B5. Dort sind sie der Čaka-Kultur zugeordnet.

\section{Branč (Paulík 1963, Nr. 8)}

Siedlung; Hütte und vier Gruben. Übergangsstufe zwischen dem Vorčaka-Horizont und der ČakaKultur. Auswahl der Keramik (Paulík 1963, Abb. 14; 1t. S. 317 aus der Grube 29, Anm. d. Verf.). Auf der Abbildung bei J. Paulík (1963, Abb. 40: J28) eine Schüssel des Vorčaka-Horizontes.

Dolné Otrokovce (Paulík 1963, Nr. 17)

Körpergräber. Vorčaka-Horizont und Čaka-Kultur. Ohne Abbildung.

Dražovce (jetzt Nitra-Dražovce; Paulík 1963, Nr. 18)

a) Streufunde; Keramik, u. a. eine Schüssel (Paulík 1963, Nr. 18, Abb. 18: 2). Vorčaka-Horizont.

b) Brandgrab; sechs Gefäße und eine Bronzenadel. Die Gefäße sind verschollen, nur die Zeichnung der Bronzenadel ist vorhanden (Paulík 1963, Nr. 18, Abb. 18: 1). Vorčaka-Horizont.

Horné Semerovce (Paulík 1963, Nr. 22)

Bronzefunde aus gestörten Brandgräbern (Paulík 1963, Abb. 21). Vorčaka-Horizont.

Horné Lefantovce (Paulík 1963, Nr. 23)

Siedlung; Hütte. Vorčaka-Horizont und Čaka-Kultur. Auswahl der Keramik (Paulík 1963, Abb. 20).

Mlynárce (Nr. 43; jetzt Nitra-Mlynárce)

Gräber. Vorčaka-Horizont. Ohne Abbildung.

Polný Kesov (Paulík 1963, Nr. 49)

a) Siedlung. Teil einer Grube. Keramik mit Reminiszenzen an die Madarovce-Kultur, solche der ausklingenden Karpatenländischen Hügelgräberkultur mit neuen Elementen und die der Čaka-Kultur. Auswahl der Keramik des Vorčaka-Horizontes und der Čaka-Kultur (Paulík 1963, Abb. 27).

b) Ein allein stehendes Hügelgrab.

Salka (Paulík 1963, Nr. 52)

a) Ein allein stehendes Hügelgrab.

b) Gräber 66, 85 u. w. (ohne weitere Angaben, Anm. d. Verf.) im Gräberfeld der Karpatenländischen Hügelgräberkultur mit Keramikinventar vom Vorčaka-Charakter. Auf der Abb. 40: H22 bei J. Paulík (1963) eine Schüssel des Vorčaka-Horizontes von Salka (Salka I, Grab 161, Anm. d. Verf.).

Sládečkovce (jetzt Sládečkovce-Močenok; Paulík 1963, Nr. 54)

Siedlung. Eine Grube der Čaka- und eine weitere der Čaka-Velatice-Kultur (Paulík 1963, Abb. 28). Auf der Abbildung bei J. Paulík (1963, Abb. 40: G19) ein Doppelkonus des Vorčaka-Horizontes. Anm. d. Verf.: Im Jahre 1960 wurden beide Gruben dem Vorčaka-Horizont zugeordnet (Paulík 1960, Abb. 155).

Tekovský Hrádok (Paulík 1963, Nr. 63a)

Unterteil eines Kruges aus der Grabung von B. Novotný. Vorčaka-Horizont (Paulík 1960, Abb. 32). 


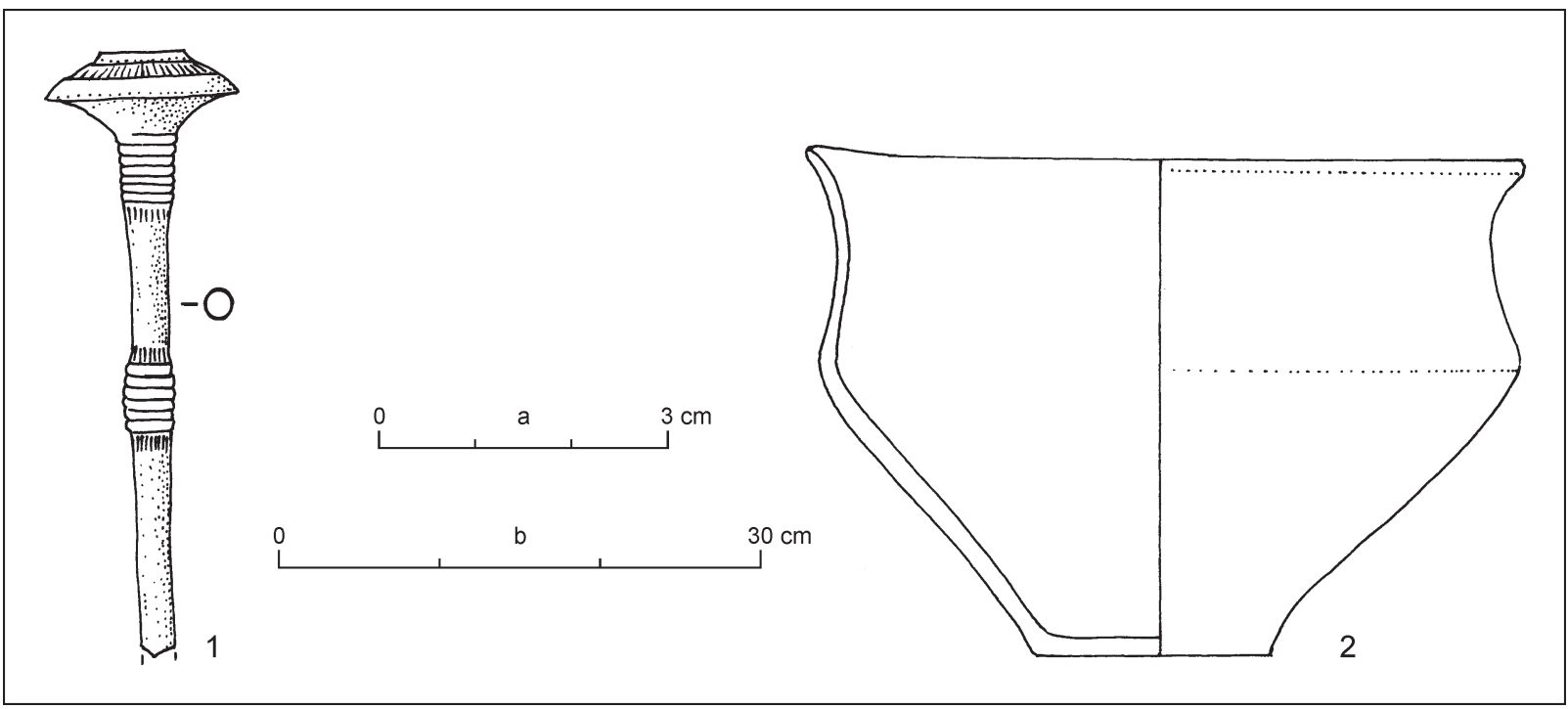

Abb. 1. Dražovce. 1 - Bronzenadel von der Fundstelle „b“; 2 - Gefäß von der Fundstelle „a“ (nach Paulík 1963). Maßstab: $a-1 ; b-2$.

\section{Topol'čany (Paulík 1963, Nr. 66)}

a) Siedlung. Vorčaka-Horizont und Čaka-Kultur. Auf der Abb. 34 bei J. Paulík (1963) eine Bronzenadel und Keramik des Vorčaka-Horizontes, auf der Abb. 40: E13 bei J. Paulík (1963) eine Schüssel dieses Horizontes.

b) Körpergrab (?). Vorčaka-Horizont.

Aus dieser Aufzählung der Fundstellen ist zu ersehen, dass die Funde des Vorčaka-Horizontes und der Čaka-Kultur in Horné Lefantovce in einer Hütte und in Polný Kesov in einer Grube zusammen vorkamen; zu ihnen wird weiter unten Stellung bezogen.

Die kulturelle Bewertung der Funde von Bešeňov, Branč sowie Sládečkovce - bei Bešeňov auch die Darstellung der Fundumstände- ist divergierend und zu den Körpergräbern von Dolné Otrokovce sind keine Angaben vorhanden. Unter diesen Umständen wären die Informationen über den Fundbestand des Vorčaka-Horizontes in erster Linie von jenen Fundstellen zu erwarten, die ausschließlich diesem Horizont angehören, ferner von der Zusammenstellung der Gefäßtypen dieses Horizontes in der Siedlung von Topoľ̌any und schließlich von den Repräsentanten dieses Horizontes im Vergleich mit jenen der Čaka-Kultur und von Vál I (Paulík 1963, Abb. 34; 40).

Ausschließlich dem Vorčaka-Horizont gehören nach J. Paulík die Fundstellen Dražovce, Horné Semerovce, Mlynárce, einige Gräber aus dem Gräberfeld der Karpatenländischen Hügelgräberkultur von Salka (Salka I, Anm. d. Verf.), Tekovský Hrádok und die Fundstelle „b“ von Topolčany an. In Dražovce (Abb. 1) könnte die Bronzenadel nur für die Datierung der sechs verschollenen Gefäße von der Fund-

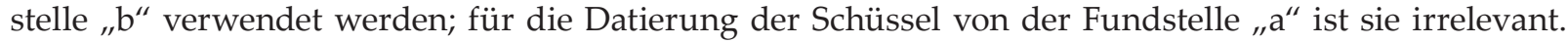
Von M. Novotná (1980, Nr. 454) wurde diese Nadel als eine Variante der Nadeln vom Typ Göggenhofen gewertet. Die große Schüssel von der Fundstelle „a“" die u. a. mit einem Fragment vom trichterförmigen Hals einer Amphore vergesellschaftet war, findet eine gute Entsprechung im Grab 3 im Hügelgrab von Farkasgyepű, Pörös-erdő I; dieses Hügelgrab mit 15 Gräbern wird von K. Jankovits in die Stufen BD/HA1 datiert (Jankovits 1992a, 77, Abb. 14: 1).

Unter den Bronzefunden von Horné Semerovce (Abb. 2) finden sich keine Typen, die eine spätere Datierung als eine in die mittlere Bronzezeit berechtigen würden; sie sind nur dahin zu interpretieren, dass es in diesem Ort ein Gräberfeld wie z. B. in Salka I gab (Točík 1964, Abb. 6; 7). Die Petschaftkopfnadel gehört nach M. Novotná dem Typ Göggenhofen an (Novotná 1980, Nr. 451).

Bei den Gräbern von Mlynárce handelt es sich nach J. Říhovský, der die unpublizierten Funde in Autopsie kannte, um zwei Brandgräber der älteren Phase der Velatice-Kultur westlicher Prägung im

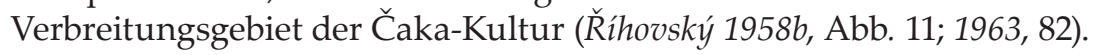

Das Inventar des Grabes 66 und einige Elemente aus dem Grab 85 der Karpatenländischen Hügelgräberkultur von Salka I wurden sowohl von J. Paulík als auch von A. Točík mit dem Vorčaka- 
Horizont bzw. der Vorčaka-Kultur in Zusammenhang gebracht (Paulík 1963, 302; Točík 1964, 50). Nach O. Oždáni gehört eventuell auch noch das Grab 61 dazu (Ožd’áni 1986, 68; 2015, 161). Das Grab 85 kann aber nicht diesem Horizont zugeordnet werden, da der Typ der verkehrt herzförmigen Anhänger nach V. Furmánek nicht später als in die mittlere Hügelgräberzeit datiert werden kann (Furmánek 1980, 30, Nr. 483-485; Točík 1964, Taf. XVIII: 9, 10). Die Tasse aus dem Grab 66 ist hingegen tatsächlich als ein fremdes Element in diesem Gräberfeld zu bezeichnen (Točík 1964, Taf. XV: 1), aufgrund ihrer Form und ihres hochgezogenen, dachförmig gekanteten Bandhenkels wäre sie aber den Tassen der Čaka-Kultur zuzuordnen (z. B. Kaus 1993-1994, Taf. 6: 2; Novotná/Novák 2015, 81; Paulík 1966, Abb. 18: 3, 4). Dieses Grab kam beim Pflügen außerhalb der Grabungsfläche zum Vorschein, aber die Geschlossenheit seines Inventars wird durch das Vorkommen einer charakteristischen Tasse der Čaka-Kultur und einer Amphore, die m. E. der Karpatenländischen Hügelgräberkultur angehört, in der Grube 1 der Velatice-Kultur von Suchá nad Parnou gestützt; bedauerlicherweise ist über die Metallfunde, die am Rande dieser Grube zum Vorschein kamen, nichts bekannt (Novotná/Novák 2015, Abb. 1: 3; 3: 5; Točík 1964, Taf. XI: 6; XXIV: 1 u. w.).

Zum Befund des Unterteils eines Kruges mit senkrechter Rillenverzierung von Tekovský Hrádok liegen keine Angaben vor, deswegen sei nur auf das Vorhandensein eines solchen Kruges in der Siedlung der Čaka-Kultur von Ipel'ský Sokolec hingewiesen (Paulík 1963, Abb. 22: 19; 32).

Bei der Veröffentlichung des unsicheren Körpergrabes mit nicht gesichertem Inventar von Topol'čany (Fst. "b“) wies V. Budinský-Krička darauf hin, dass die kleine Amphore sowohl in die Hallstattzeit als auch ins Äneolithikum datiert werden könnte (Budinský-Krička 1952, 34 f., Abb. 29 oben). Im Jahre 1984 wurde dieses Gefäß von E. Wiedermann als eines der Lengyel-Kultur ohne nähere Angaben zum Befund republiziert (Wiedermann 1985, Nr. 108, 29, 91, Taf. XII: 4).

Es ist äußerst bedauerlich, dass die Funde von der Siedlung von Topolčany noch immer nicht veröffentlicht sind. Es sei erwähnt, dass M. Novotná im Jahre 1995 Skepsis hinsichtlich der Zugehörigkeit dieser Siedlung zum Vorčaka-Horizont wegen der Andersartigkeit der Keramik anklingen ließ (Novotná 1995, 374, Anm. 7) und dass L. Veliačik und P. Romsauer sie für eine Siedlung der Čaka-Kultur hielten (Veliačik/Romsauer 1994, 199).

Zuerst ist darauf aufmerksam zu machen, dass die von J. Paulík abgebildete Nadel vom Typ Hradec bzw. Vel'ká Lehota außerhalb der Siedlung zutage kam (Abb. 3: 1; Novotná 1980, 112 f.; Paulík 1963, Abb. 34: 1; Veliačik/Romsauer 1994, 199), sodass sie nicht zur Datierung dieser zugezogen werden kann. Das bedeutet, dass -so wie bei Dražovce und Horné Semerovce - auch in Topolčany die Datierung des Vorčaka-Horizontes in die Stufe C bzw. den Übergang der Stufen C/D über keine Stütze durch Bronzegegenstände verfügt. Die Siedlung selbst bestand nach L. Veliačik und P. Romsauer aus sieben Gruben (Nr. 2-8) und fünf als Hütten bezeichneten eingetieften Siedlungsobjekten unterschiedlicher Form, wobei es sich aber bei der Hütte 5 eher um einen Grubenkomplex oder eine Lehmentnahmegrube handeln dürfte (Nr. 2-6; Veliačik/Romsauer 1994, 197, 199). Eine kleine Auswahl der Funde wurde von J. Paulík (1960, Abb. 154), eine größere von A. Toč́k und J. Paulík (1960, Abb. 28-31) veröffentlicht, die Funde sind aber leider nicht immer verlässlich identifizierbar. Dass die veröffentlichten Funde nur einen Teil der Gefäßtypen aus den einzelnen Fundkomplexen repräsentieren, ist aus der ergänzenden Auswahl der Keramik aus der Hütte 5 zu ersehen, die im Jahre 1999 publiziert wurde (Furmánek/Veliačik/Vladár 1999, Abb. 31: 34-46). Unter den gegebenen Umständen kann es sich bei den Anhaltspunkten zur Datierung der Siedlung nur um vorläufige Erkenntnisse handeln.

Die Keramiktypen des Vorčaka-Horizontes aus dieser Siedlung stellte J. Paulík zusammen (Abb. 3). Sie stammen, soweit es sich feststellen ließ, aus vier Hütten und drei Gruben: 


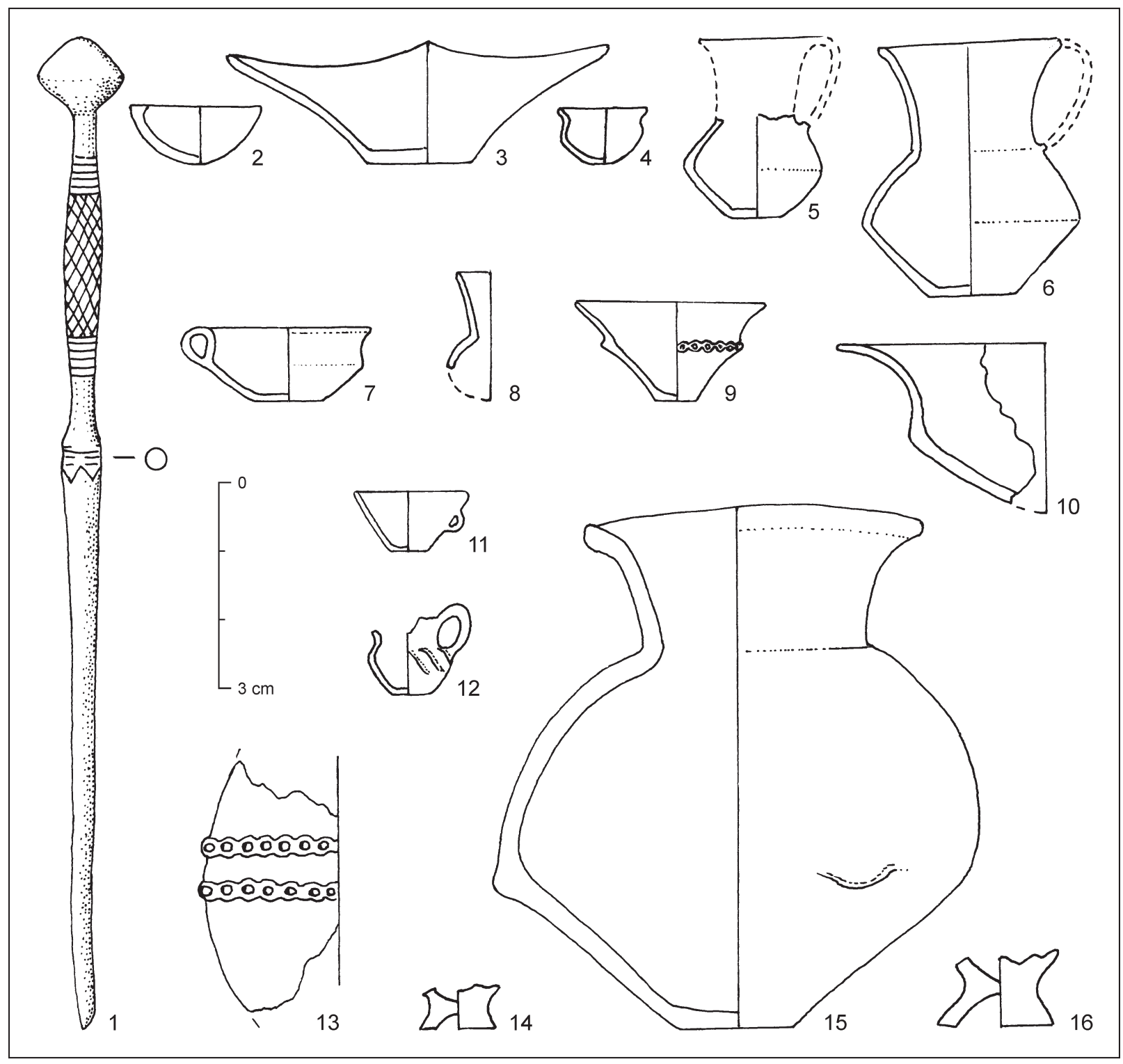

Abb. 3. Topol'čany, Stadion. 1 - Bronzenadel, Einzelfund; 2-16 - Auswahl der Keramik aus der Siedlung (ohne Maßstab; nach Paulík 1963).

Nr. 2, 3 (?), 10, 15, 16:

Nr. 4, 5, 8, 14:

Nr. 6:

Nr. 7:

Nr. 9:

Nr. 11, 12:

Nr. 13:
Grube 8

Hütte 4

Hütte 2

Hütte 5 (?)

Hütte 6

Grube 4

Grube 6
(Paulík 1960, Abb. 154: 1, 2; Točík/Paulík 1960, Abb. 30: 1).

(Paulík 1960, Abb. 154: 7; Točík/Paulík 1960, Abb. 30: 2).

(Paulík 1960, Abb. 154: 8).

(Toč́k/Paulík 1960, Abb. 28: 1 unten rechts).

(Točík/Paulík 1960, Abb. 29: 2).

(Točík/Paulík 1960, Abb. 28: 5).

(Točík/Paulík 1960, Abb. 28: 2).

In die typologische Tabelle der Vorčaka-Keramik wurden fünf Gefäße aus der Grube 8 aufgenommen. An Amphoren berücksichtigte man die Amphore mit trichterförmigen Hals und Lappen auf der größten Wölbung aus der Grube 8, diese Grube enthielt aber mehrere Amphoren unterschiedlicher Typen (Abb. 3: 15; 4: 1-4, 21). Sie sind als Typ auch in der Grube 6 und in den Hütten 3-6 vorhanden, d. h. in der Hälfte der Fundkomplexe (Točík/Paulík 1960, Abb. 28-30). J. Paulík war sich der Tatsache bewusst, dass es sich bei den Amphoren um einen im Großteil der mitteleuropäischen Kulturen verbreiteten Gefäßtyp des älteren Abschnitts der jüngeren Bronzezeit handelt, u. a. auch in der Velatice-Kultur (Paulík 1963, 289). Diese Tatsache 


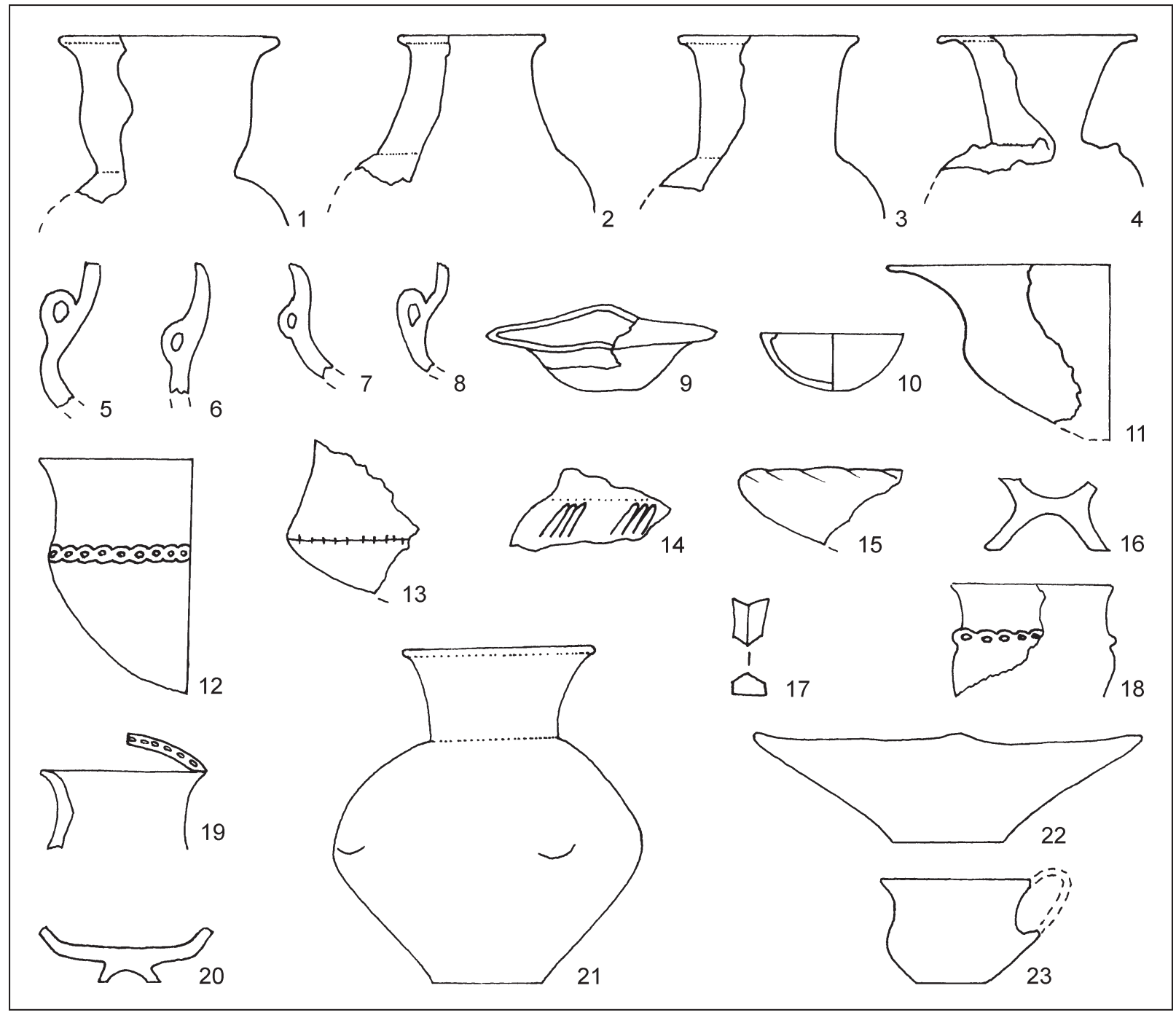

Abb. 4. Topol'čany, Stadion. Auswahl der Keramik aus der Grube 8 (nach Točík/Paulík 1960 und Paulík 1960, Nr. 21-23). Ohne Maßstab.

wirkte sich darin aus, dass die von J. Paulík übernommene, von ihm dem Vorčaka-Horizont zugesprochene Amphore von Bešeňov von anderen Autoren als ein Gefäß der älteren Mitteldonauländischen Urnenfelderkultur bzw. der Velatice-Kultur gewertet wurde (Furmánek/Veliačik/Vladár 1991, Abb. 12: 20; 1999, Abb. 29: 20; Ožd’áni 2015, Abb. 155; Paulík 1963, Abb. 40: F16). Die Innenkantung des Mundsaumes der amphorenartigen Gefäße ist nach J. Říhovský ab der Stufe Blučina nachgewiesen (Blučina-Kopčany: Ǩíhovský 1982, 37 f.), für die Datierung der Amphoren aus der Grube 8 ist aber ihre Vergesellschaftung mit einer Etagenhalsamphore von entscheidender Bedeutung (Abb. 4: 1). Nach J. Ř́hovský kommen die Amphoren mit derart profilierterem Hals in Südmähren, Niederösterreich, im Burgenland, in der Südwestslowakei und in Nordwestungarn erst in der Stufe HA auf (Ř́hovský 1958a, 94, Abb. 41; Salaš 1993, 297). Das bezieht sich auch auf eine Amphore aus dem Grab 5 von Zohor (Studeníková 1978, 30, Abb. 10: 4). Erst zu dieser Zeit setzen auch die Schüsseln mit eingezogenem und schräg gerilltem Rand an; eine Schüssel dieser Art war z. B. im Grab I von Velatice enthalten (Abb. 4: 15; Říhovský 1958b, 91; 1963, Abb. 14: 13; 1967, 38, Taf. IV: 84). Auch das Vorkommen einer S-förmig profilierten Schale mit hochgezogenem Bandhenkel (Abb. 4: 23) steht mit dieser Datierung im Einklang; dieser Gefäßtyp war nicht nur in der Grube I von Sládečkovce (Paulík 1963, Abb. 28: 1, 3), sondern auch in den Gräbern von Očkov, Großhöflein und Gemeinlebarn mit Kolbenkopfnadeln vergesellschaftet (Szombathy 1929, Taf. 21: 5, 6; Pittioni 1941, Taf. XII: 7, 12; Paulík 1962b, Abb. 15: 1, 2; 20: 13), wenngleich sein Auftreten nicht auf diese Stufe beschränkt ist (z. B. Říhovský 1963, Taf. 10B: 9; Lochner 1986, Taf. 6: 4). Mit der Grube 8 befindet man sich also in der Stufe Velatice-Očkov, d. h. in der Stufe HA1. 
Ein Fragment der Schüssel mit geknickter Wand und weit ausladendem Rand (Abb. 3: 10; 4: 11) repräsentiert die sog. "Čakaer Schüsseln“ J. Paulíks; eine von ihnen fand sich im Brandgrab III von Čaka (Paulík 1963, 290 f.; Točík/Paulík 1960, Abb. 25: 1). Schüsseln dieser Art gehören zum Typenschatz der spätbronzezeitlich/frühurnenfelderzeitlichen Hügelgräberkultur in Transdanubien (Jankovits 1992b, Abb. 65: 10); im Grab 6 von Balatonfüzfő war eine Schüssel dieser Art u. a. mit einem Messer vom Typ Baierdorf vergesellschaftet, wobei dieses Grab auch in Bezug auf das gemeinsame Vorkommen der Amphore und der Schüssel mit dem Inventar der Grube 8 von Topolčany vergleichbar ist (Ilon 2012, 93, Taf. 2: 2; 4: 1, 5). Einer Vergesellschaftung der beiden erwähnten Gefäßtypen begegnet man auch im Grab 2 von Németbánya, und zwar in Begleitung eines doppelkonischen Gefäßes mit gekerbtem Umbruch; auch dieser Gefäßtyp ist in der Grube 8 von Topolčany vertreten (Abb. 4: 13; Ilon 1987, Taf. II).

Die Schüssel mit gelapptem Rand (Abb. 3: 3; 4: 22) ist ein charakteristischer Gefäßtyp der Mitteldonauländischen Hügelgräberkultur (z. B. Bartík 1996, Abb. 3, D 59; 2004, Abb. 8: 4, 5; 10: 1, 4; 13: 1; Bartík/ Elschek/Varsik 2013, Abb. 17 unten; Lauermann/Hahnel 1998-1999, Taf. 2: 9; Stuchlík 1990, 2: 1; 3: 2; 4: 7; 1993, Abb. 175: 5; 176: 10); ob die Schüssel Abb 4: 22 mit der kleinen Schüssel Abb. 4: 9 identisch ist, lässt sich nicht beurteilen. Aufgrund ihrer bereits erwähnten Begleitfunde ist die Datierung dieser Schüssel in den Vorčaka-Horizont ausgeschlossen. Verschiedene Varianten der konischen Schüsseln mit Randlappen haben eine lange Lebensdauer bis in die Urnenfelderzeit hinein (z. B. Kemenczei 1990, Abb. 12: 9, 11; Palátovál Salaš 2002, Tab. 17: 7; Patek 1968, Taf. VI: 23, 27; Ř́hovský 1982, Taf. 45: 5).

Die kleine Schüssel mit waagrechtem, nach innen verbreitertem Rand (Abb. 3: 2; 4: 10) erinnert an die Schüsseln der Madarovce-Kultur, worauf schon J. Paulík hinwies (Paulík 1963, 292; Typ D 4 nach Točík 1981, Beil. 1), ähnliche Schüsseln sind aber nicht nur in den von J. Paulík mit dem Vorčaka-Horizont in Zusammenhang gebrachten Fundstellen, sondern auch in der durch eine Kolbenkopfnadel datierten Grube I von Sládečkovce und in der Siedlung der Velatice-Kultur von Senec vorhanden (Paulík 1963, 292, Abb. 14: 11; 20: 3; 28: 5; 1972, Taf. III: 6).

Dass ein Hohlfüßchen (Abb. 3: 16; 4: 16) nicht für ein Spezifikum des Vorčaka-Horizontes gehalten werden kann, sei an der Keramik aus dem Grab von Marcelová und dem Grab IV von Čaka gezeigt (Paulík 1962a, Abb. 1: 5; 1963, Abb. 6: 14).

Aus der Hütte 4 stammen ein scharf profilierter Unterteil eines Kruges und ein Teil eines schlanken hochhalsigen Kruges (Abb. 3: 5, 8; Toč́k/Paulík 1960, Abb. 30: 2). Der Krug mit scharf profiliertem Unterteil aus der Hütte 2 wurde leider ohne Begleitfunde abgebildet (Abb. 3: 6; Paulík 1960, Abb. 154: 8). Ein solcher Krug fand sich nach einer ergänzenden Auswahl der Funde auch in der Hütte 5 (Furmánek/Veliačik/Vladár 1999, Abb. 31: 34-46). Alle genannten Krüge finden in der Karpatenländischen Hügelgräberkultur keine Vorlagen; die scharf profilierten können mit der Mitteldanubischen Hügelgräberkultur in Verbindung gebracht werden, was schon J. Paulík aufzeigte (Bartík 1996, Taf. 2: 1; Palátová/Salaš 2002, Taf. 1: 6; Paulík 1963, 317). Vergleichbare Krüge sind aber auch in der Siedlung der Čaka-Kultur in Ipel'ský Sokolec und in der Siedlung der VelaticeKultur von Senec vorhanden (Paulik 1972, Taf. III: 7; 1963, Abb. 22: 18). Einer solchen Datierung entsprechen die Begleitfunde der Krüge in den Hütten 4 und 5 von Topolčany, u. a. die Amphoren mit Innenkantung des Mundsaumes und die typische Čaka-Schüssel (Toč́k/Paulík 1960, Abb. 28: 1; 30: 2). Deswegen ist die Datierung der Hütte I/80 von Dedinka, das nach J. Paulík vorwiegend die Keramik der Čaka-Kultur enthielt, in den Vorčaka-Horizont aufgrund des Kruges mit scharf profiliertem Unterteil nicht überzeugend (Paulík 1992, 48, Abb. 5). Eine Datierung in die Zeit der voll ausgebildeten Čaka-Kultur bezieht sich auch auf die kleine Schale und das Hohlfüßchen eines Gefäßes (Abb. 3: 4, 14) aus der Hütte 4 von Topolčany.

Aus der Grube 4 wurden von J. Paulík zwei Gefäße in der Tabelle der Gefäßtypen des VorčakaHorizontes berücksichtigt, und zwar eine kleine konische Tasse und eine hohe Tasse mit hochgezogenem Bandhenkel und schräg gerillter Schulter (Abb. 3: 11, 12). Bei der konischen Tasse handelt es sich um einen im Rahmen der mittleren und späten Bronzezeit kulturell und chronologisch unempfindlichen Gefäßtyp (Ǩ́hovský 1982, 45), die hohe verzierte Tasse findet eine annähernde Entsprechung in Blučina (Ř́hovský 1963, Taf. 6: 8); in der Grube 4 wurden diese Gefäße u. a. von einer typischen Schüssel der ČakaKultur (Toč́k/Paulík 1960, Abb. 28: 5) begleitet. In der Lausitzer Kultur in der Slowakei gehören solche Schalen zum Typenschatz der Stufe IV (HA1) nach L. Veliačik (1983, Abb. 7: IV-B1; 8).

Die letzten drei Gefäße in der Typentabelle sind eine Henkelschale, eine kleine Schüssel und ein Teil eines gebauchten Gefäßes. Der Fundzusammenhang der Schale mit kehligem Rand (Abb. 3: 7) lässt sich leider nicht einwandfrei eruieren; es kann nur angenommen werden, dass sie aus der Hütte 5 stammt (Točík/Paulík 1960, Abb. 28). Bei ihr handelt es sich um den Schalentyp 2 der Stufe Blučina mit Wurzeln in der jüngeren mitteldonauländischen Hügelgräberkultur ( Schüssel mit Grübchenleiste (Abb. 3: 9) aus der Hütte 6 sind mir keine Vergleichsmöglichkeiten bekannt; 
die Datierung dieser Hütte wurde bereits erörtet. Das Fragment eines gebauchten Gefäßes mit doppelter Grübchenleiste (Abb. 3: 13) aus der Grube 6 findet eine durch ein Messer vom Typ Baierdorf verlässlich datierte Analogie im Hügelgrab von Isztimér-Csőszpuszta (Kustár 2000, 25, Taf. 15: 6). Damit sind auch die Schalen mit schräg gerillter Schulter aus der Grube 6 und der Hütte 4 in diesen Zeitabschnitt datiert (Paulík 1960, Abb. 154: 5; Točík/Paulík 1960, Abb. 30: 2).

Die kurze Übersicht der in der Tabelle des Vorčaka-Horizontes enthaltenen Keramiktypen von Topolčany zeigt, dass sie aus Fundverbänden der Stufen BD und HA1 mit einem starken Anteil der Keramik der Velatice-Kultur stammen.

Schließlich sind einige Gefäßtypen des Vorčaka-Horizontes aus der Südwestslowakei zu erwähnen, die diesen Horizont im Vergleich mit verwandten Typen der Čaka-Kultur und von Vál I repräsentieren sollen (Paulík 1963, Abb. 40). Zur Schüssel von Topol'čany und der Amphore von Bešenov (Paulík 1963, Abb. 40: E13, F16) wurde bereits Stellung genommen. Die Berücksichtigung des doppelkonischen Gefäßes von Sládečkovce (Paulík 1963, Abb. 40: G19) geht auf die bereits erwähnte Zuordnung der Fundstelle zum VorčakaHorizont im Jahre 1960 zurück, die im Jahre 1963 nicht mehr gültig war (Paulík 1960, Abb. 155: 10; 1963, 302 f.). Die Schüssel von Salka I (Paulík 1963, Abb. 40: H22) könnte zwar durchaus für einen Vorläufer der Schüsseln mit gelapptem Rand der Čaka-Kultur gehalten werden, aber Schüsseln dieser Art sind auch im Fundgut der benachbarten Piliny-Kultur anzutreffen (Typen II und V nach Furmánek 1977, Abb. 6). Der Fundzusammenhang der mit einer Grübchenreihe (?) verzierten Schüssel von Branč (Paulík 1963, Abb. 40: J28) ist unbekannt.

Das gemeinsame Vorkommen der mittel- und spätbronzezeitlichen Keramik in Horné Lefantovce, Polný Kesov und Topolčany entspricht der Situation im Gräberfeld von Zohor sowie in den Siedlungen von Suchá nad Parnou und Strachotín. Das Grab 7 von Zohor, das u. a. einen Krug und eine Tasse der Mitteldonauländischen Hügelgräberkultur, aber auch ein scharf profiliertes doppelkonisches Gefäß enthielt, wurde in die Stufe Blučina-Kopčany, die Stufe Strachotín-Velké Hostěrádky bzw. in die ältere mitteldonauländische Urnenfelderkultur gesetzt (Furmánek/Veliačik/Vladár 1991, Abb. 12: 6, 10, 14; 1999, Abb. 29: 6, 10; Říhovský 1982, 15, Abb. 62A; Studeníková 1978, 37, Abb. 11: 1, 3) und die Grube 1 von Suchá nad Parnou, die u. a. je ein Gefäß der Karpatenländischen Hügelgräberkultur und der Čaka-Kultur barg, in die zweite Stufe der Velatice-Kultur datiert (Novotná/Novák 2015, 81). Das Nebeneinander der Keramikformen der jüngeren und späten Stufe der Mitteldonauländischen Hügelgräberkultur und der frühen und älteren Stufe der Mitteldonauländischen Urnenfelderkultur wurde durch die Gruben 222 und 1/75 von Strachotín sehr eindrucksvoll nachgewiesen (Ř́hovský 1982, 13 f., Taf. 28-31A). Im Bereich der Velatice-Kultur werden also seit den achtziger Jahren des 20. Jh. die kulturell "gemischten“ Fundverbände nach den ,jüngeren“ Funden datiert, während J. Paulík solche Fundverbände im Bereich der Čaka-Kultur in den sechziger Jahren und auch noch später nach den „älteren“ Funden datierte. Aber bereits in den achtziger Jahren begegnet man auch einer anderen Vorgangsweise bei der Datierung eines Čakaer Fundkomplexes; die Grube 1 von Šarovce, die u. a. eine Amphore der Karpatenländischen Hügelgräberkultur barg, wurde der Čaka-Kultur zugeordnet (Novotný/Novotná 1981, 241, Abb. 10). Da es bei den erwähnten gemeinsamen Gefäßtypen der Velatice- und der Čaka-Kultur keine Nachweise für ihr früheres Auftauchen in der Čaka-Kultur gibt, sollten alle in der J. Paulíks Fundliste enthaltenen Fundkomplexe, die neben der Keramik der Čaka-Kultur auch die der Hügelgräberkultur enthalten, in die Zeit der vollentwickelten Čaka-Kultur datiert werden.

Mit den Gruben von Šarovce, Suchá nad Parnou, den in der Liste J. Paulíks enthaltenen kulturell „,gemischten" Fundkomplexen und wohl auch mit dem Grab 66 von Salka I beginnt sich auch im Gebiet der Karpatenländischen Hügelgräberkultur in der Südwestslowakei ein Nebeneinander der jüngsten Phase der genannten Kultur und der ältesten Phase der mitteldonauländischen Urnenfelderkultur abzuzeichnen, das im Gebiet der Mitteldonauländischen Hügelgräberkultur in Mähren von J. Ř́hovský durch die teilweise gleichzeitige Existenz der Stufen Strachotín-Velké Hostěrádky und Blučina-Kopčany im Jahre 1982 nachgewiesen wurde (Ǩíhovský 1982, chronologische Tabelle auf S. 91).

Zusammenfassend kann gesagt werden, dass die Existenz des Vorčaka-Horizontes in der Slowakei sich auf der Grundlage der von J. Paulík im Jahre 1963 vorgelegten Auswahl der Funde nicht bestätigen lässt. Der Autor war sich der Probleme, die sich aus dem Vorkommen derselben Gefäßtypen in der Čakaund in der Velatice-Kultur ergeben, bewusst, aber die Prämisse über die Entstehung einer „karpatischen Velatice-Baierdorf-Kultur" aus der Čaka-Kultur zwang ihn zur weitgehenden Negierung des Vorhandenseins der Velatice-Kultur im Čaka-Verbreitungsgebiet (Paulík 1963, 292 f., 320 ff.). Deswegen kann die Frage der Entstehung bzw. der Herkunft der Čaka-Kultur und ihres Habitus erst nach der Veröffentlichung der Fundquellen der mittleren und späten Bronzezeit, ihrer gründlichen, unvoreingenommenen Auswertung und ihrem Vergleich mit Niederösterreich sowie Südmähren auf der einen Seite und Nordtransdanubien sowie Nordburgenland auf der anderen Seite sinnvoll beurteilt werden. 


\section{LITERATUR}

Bartík 1996

Bartík 2004

Bartík/Elschek/Varsik 2013

Benkovsky-Pivovarová 2015

Budinský-Krička 1952

Furmánek 1977

Furmánek 1980

Furmánek 1981

Furmánek/Veliačik 1980

Furmánek/Veliačik/Vladár 1991

Furmánek/Veliačik/Vladár 1999

Ilon 1987

Ilon 2012

Jankovits 1992a

Jankovits $1992 b$

Kaus 1993-1994

Kemenczei 1990

Kustár 2000

Lauermann/Hahnel 1998-1999

Lochner 1986

Novotná 1980

Novotná 1984

Novotná 1995

Novotná/Novák 2015

Novotný/Novotná 1981
J. Bartík: Sídlisko stredodunajskej mohylovej kultúry vo Veselom. Slovenská archeológia 44, 1996, 189-252.

J. Bartík: Hromadný nález keramiky z Lozorna. Príspevok ku keramickým depotom stredodunajskej mohylovej kultúry na západnom Slovensku. Zborník SNM 98. Archeológia 14, 2004, 9-42.

J. Bartík/K. Elschek/V. Varsik: Praveké sídlisko v Lozorne-Širokých dieloch (západné Slovensko). Výskumy v rokoch 1999-2009. Zborník SNM. Archeológia. Supplementum 7. Bratislava 2013.

Z. Benkovsky-Pivovarová: Zur Terminologie der bronzezeitlichen Hügelgräberkultur in Mitteleuropa. Zborník SNM 109. Archeológia 25, 2015, 73-88.

V. Budinský-Krička: Nové nálezy v Topol’̌̌anoch. Archeologické rozhledy 4, 1952, 33-35, 42-45.

V. Furmánek: Pilinyer Kultur. Slovenská archeológia 25, 1977, 251-370.

V. Furmánek: Die Anhänger in der Slowakei. Prähistorische Bronzefunde 11. München 1980.

V. Furmánek: The Bronze Age. In: Archaeological Research in Slovakia. $10^{\text {th }}$ International Congress of Prehistoric and Protohistoric Sciences, Mexico 19.-24. October 1981. Nitra 1981, 61-83.

V. Furmánek/L. Veliačik: Doba bronzová. Slovenská archeológia 28, 1980, 159-179.

V. Furmánek/L. Veliačik/J. Vladár: Slovensko v dobe bronzovej. Bratislava 1991.

V. Furmánek/L. Veliačik/J. Vladár: Die Bronzezeit im slowakischen Raum. Prähistorische Archäologie in Südosteuropa 15. Rahden/Westfalen 1999.

G. Ilon: Egy sírépítménytípus a Bakony-vidéki kesőbronzkorban. Elözetés jelentés (2.) az 1984. Évi Németbánya-Felsőerdei-dülői ásatásról. A Veszprém Megyei Múzeumok Közleményei 18, 1986, 1987, 83-93.

G. Ilon: Ein weitere Bestattung der frühurnenfelderzeitlichen Elite - das Grab Nr. 6 aus Balatonfüzfó (Ungarn, Komitat Veszprém). In: R. Kujovský/V. Mitáš (ed.): Václav Furmánek a doba bronzová. Zborník k 70. narodeninám. Archaeologica Slovaca Monographiae. Communicationes XIII. Nitra 2012, 137-150.

K. Jankovits: Spätbronzezeitliche Hügelgräber in der Bakony-Gegend. Acta archaeologica Academiae Scientiarum Hungaricae 44, 1992, 3-81.

K. Jankovits: Spätbronzezeitliche Hügelgräber von Bakonyjákó. Acta Archaeologica Akademiae Scientiarum Hungaricae 44, 1992, 261-343.

M. Kaus: Ein mittelbronzezeitliches Hügelgrab mit Čaka-Nachbestattung von Neusiedl-Hutweide, Burgenland. Mitteilugen der Anthropologischen Gesellschaft in Wien 123/124, 1993/1994, 89-109.

T. Kemenczei: Der ungarische Donauraum und seine Beziehungen am Ende der Hügelgräberbronzezeit. In: Beiträge zur Geschichte und Kultur der mitteleuropäischen Bronzezeit. Berlin-Nitra 1990, 207-228.

R. Kustár: Spätbronzezeitliches Hügelgrab in Isztimér-Csőszpuszta. Alba Regia 29, 2000, 7-53.

E. Lauermann/B. Hahnel: Die mittelbronzezeitlichen Gefäßdepots von Großmugl in Niederösterreich. In: A. Krenn-Leeb/J.-W. Neugebauer (Hrsg.): Depotfunde der Bronzezeit im mittleren Donauraum. Archäologie Österreichs 9/10. Wien 1998/1999, 88-102.

M. Lochner: Das frühurnenfederzeitlich Gräberfeld von Baierdorf, Niederösterreich - eine Gesamtdarstellung. Archaeologia Austriaca 70, 1986, 263-293.

M. Novotná: Die Nadeln in der Slowakei. Prähistorische Bronzefunde XIII-6. München 1980

M. Novotná: Halsringe und Diademe in der Slowakei. Prähistorische Bronzefunde XI/4. München 1984.

M. Novotná: Stand und Aufgaben der Urnenfelderforschung in der Slowakei und angrenzenden Gebieten. Beiträge zur Urnenfelderzeit nördlich und südlich der Alpen. Hermann Müller-Karpe gewidmet. Monographien des Römisch Germanischen Zentralmuseums 35, 1995, 373-387.

M. Novotná/P. Novák: Zerstörte Siedlung der mitteldanubischen Urnenfelder in Suchá nad Parnou. Zborník SNM. Archeológia. Supplementum 9. Gedenkschrift für Jozef Paulík. Bratislava 2015, 77-90.

B. Novotný/M Novotná: Siedlung der Čaka- und Velatice-Kultur von Šarovce. Arbeits- und Forschungsberichte zur sächsischen Bodendenkmalpflege. Beiheft 16. Beiträge zur Ur-und Frühgeschichte 1, 1981, 237-250. 
Ožd’áni 1986

Ožd’áni 2015

Palátová/Salaš 2002

Patek 1968

Paulík 1960

Paulík 1962a

Paulík 1962b

Paulík 1963

Paulík 1966

Paulík 1972

Paulík 1992

Pittioni 1941

Podborský s kol. 1993

Romsauer/Veliačik 1987

Říhovský 1958a

Říhovský $1958 b$

Říhovský 1963

Říhovský 1967

Říhovský 1982

Salaš 1993

Studeníková 1978

Stuchlik 1990

Stuchlik 1993

Szombathy 1929

Šabatová 2006

Točík 1964

Točík 1981

Točík/Paulík 1960

Točík/Vladár 1971

Veliačik 1983

Veliačik/Romsauer 1994

Wiedermann 1985
O. Oždáni: Zur Problematik der Entwicklung der Hügelgräberkulturen in der Südwestslowakei. Slovenská archeológia 34, 1986, 5-96.

O. Oždáni: Čakanská kultúra. In: Staré Slovensko 4. Doba bronzová. Archaeologica Slovaca Monographiae 4. Nitra 2015, 167-171.

H. Palátová/M. Salaš: Depoty keramických nádob doby bronzové na Moravě a v sousedních zemích. Pravěk Nová Řada. Supplementum 9. Brno 2002.

E. Patek: Die Urnenfelderkultur in Transdanubien. Archaeologia Hungarica. Series nova 44. Budapest 1968.

J. Paulík: K problematike mladšej doby bronzovej na juhozápadnom Slovensku. Archeologické rozhledy 12, 1960, 408-427.

J. Paulík: Čakanské pohrebisko v Marcelovej. Študijné zvesti AÚ SAV 9, 1962, 99-108. J. Paulík: Das Velatice-Baierdorfer Hügelgrab in Očkov. Slovenská archeológia 10, 1962, 5-96.

J. Paulík: K problematike čakanskej kultúry v Karpatskej kotline. Slovenská archeológia 11, 1963, 269-338.

J. Paulík: Mohyla čakanskej kultúry v Kolte. Slovenská archeológia 14, 1966, 357-396. J. Paulík: Velatická kultúra na Slovensku. Zprávy Československé společnosti archeologické 14, sešit 1-2, 1972.

J. Paulík: Osada čakanskej kultúry v Dedinke. Zborník SNM 86. Archeológia 2, 1992, 45-66.

R. Pittioni: Beiträge zur Urgeschichte der Landschaft Burgenland im Reichsgau Niederdonau. Wien 1941.

V. Podborský s kolektivem: Pravěké dějiny Moravy. Vlastivěda moravská. Země a lid. Nová řada 3. Brno 1993.

P. Romsauer/L. Veliačik: Entwicklung und Beziehung der Besiedlung der Lausitzer und mitteldonauländischen Urnenfelder in der Westslowakei. In: Die Urnenfelderkulturen Mitteleuropas. Symposium Liblice 21.-25. 10. 1985. Praha 1987, 295-304.

J. Ř́íhovský: Etážovitá osudí ve velatické kultuře. Archeologické rozhledy 10, 1958, 79-106.

J. ̌̌íhovský: Žárový hrob z Velatic I a jeho postavení ve vývoji velatické kultury. Památky archeologické 49, 1958, 67-118.

J. Říhovský: K poznání starší fáze kultury středodunajských popelnicových polí velatické kultury. Sborník Československé společnosti archeologické 3, 1963, 61-115.

J. Říhovský: Starší (velatická) fáze středodunajského okruhu kultury popelnicových polí na Moravě. Zprávy Československé společnosti archeologické př̀i Čs. akademii věd 9, 1967, 29-41.

J. Říhovský: Základy středodunajských popelnicových poli na Moravě. Studie Archeologického ústavu Československé akademie věd v Brně 10. Brno 1982.

M. Salaš: Kultura středodunajských popelnicových polí. In: Podborský s kol.1993, 286-301.

E. Studeníková: Nálezy z doby bronzovej v Zohore, okres Bratislava-vidiek. Zborník SNM 72. História 18, 1978, 9-40.

S. Stuchlík: Počátky mohylového pochovávání v době bronzové na Moravě. In: Pravěké a slovanské osídlení Moravy. Sborník k 80. narozeninám Josefa Poulíka. Brno 1990, $128-145$.

S. Stuchlík: Středodunajská mohylová kultura. In: Podborský s kol. 1993, 272-286. J. Szombathy: Prähistorische Flachgräber bei Gemeinlebarn in Niederösterreich. RömischGermanische Forschungen III. Berlin und Leipzig 1929.

K. Šabatová: K závěru vývoje mohylové kultury a počátku lužických popelnicových polí na střední a severní Moravě. Pravěk Nová řada 14, 2004, 2006, 101-122.

A. Točík: Die Gräberfelder der karpatenländischen Hügelgräberkultur. Fontes archaeologici pragenses 7. Pragae 1964.

A. Točík: Nitriansky Hrádok-Zámeček. Bronzezeitliche befestigte Ansiedlung der Mad'arovce-Kultur. Materialia Archaeologica Slovaca III. Nitra 1981.

A. Točík/J. Paulík: Výskum mohyly v Čake v rokoch 1950-1951. Slovenská archeológia 8, 1960, 59-124.

A. Točík/J. Vladár: Prehlad bádania v problematike vývoja Slovenska v dobe bronzovej. Slovenská archeológia 19, 1971, 365-422.

L. Veliačik: Die Lausitzer Kultur in der Slowakei. Studia Archaeologica Slovaca II. Nitra 1983.

L. Veliačik/P. Romsauer: Vývoj a vzt’ah osídlenia lužických a stredodunajských popolnicových polí na západnom Slovensku I. Katalóg. Archaeologica Slovaca Catalogi VI. Nitra 1994.

E. Wiedermann: Archeologické pamiatky topol'čianskeho múzea. Materialia Archaeologica Slovaca VII. Nitra 1985. 


\title{
K predčakanskému horizontu na juhozápadnom Slovensku
}

\author{
Zoja Benkovsky-Pivovarová
}

\author{
Súhrn
}

Príspevok sa zaoberá datovaním a kultúrnym postavením predčakanského horizontu na juhozápadnom Slovensku. Jeho bezprostredným dôvodom je publikovanie pohrebiska v St. Margarethen im Burgenland a s ním spätá otázka kultúrnej príslušnosti mohýl stupňa BD/HA1 vo východnom Rakúsku.

Termín „predčakanský horizont“ uviedol do literatúry J. Paulík v roku 1960. Považoval ho za pracovnú hypotézu, ktorá sa ešte musí overit d’alšími výskumami (Paulík 1960, 414 nn., 426 n.). Počiatok tohto horizontu J. Paulík datoval do stupňa BC, jeho trvanie A. Točík a J. Paulík obmedzili na prechod stupňov BC/BD. V slovenskej literatúre sa však vyskytujú aj obmeny tohto datovania, napr. do stupňov BC-BD, do stupňa BD a do obdobia neskorej mohylovej kultúry/ včasnej kultúry popolnicových polí. Predpokladá sa vývoj čakanskej kultúry z karpatskej mohylovej kultúry.

V roku 1963 J. Paulík uverejnil zoznam lokalít čakanskej kultúry, v ktorom sú zahrnuté aj lokality predčakanského horizontu. Tento zoznam je východiskom nášho príspevku.

Zoznam lokalít čakanskej kultúry zahŕňa 80 lokalít. 11 z nich J. Paulík dal aspoň do čiastočnej súvislosti s predčakanským horizontom, a to Bešeňov, Branč, Dolné Otrokovce, Dražovce, Horné Semerovce, Horné Lefantovce, Mlynárce, Polný Kesov, Salku, Tekovský Hrádok a Topoličany.

Zo stručného prehladu lokalít predčakanského horizontu, podl’a údajov J. Paulíka, vyplýva, že v chate v Horných Lefantovciach a v jame v Polnom Kesove sa keramika predčakanského horizontu vyskytla spoločne s keramikou čakanskej kultúry. Údaje k nálezom z Bešeňova, Branča a Sládečkoviec sa v otázke kultúrnej príslušnosti k predčakanskému horizontu, resp. k čakanskej kultúre, rozchádzajú. Pri Bešeňove to platí aj o údajoch k nálezovej situácii a o kostrových hroboch z Dolných Otrokoviec, kde nie sú k dispozícii žiadne údaje.

Výlučne k predčakanskému horizontu J. Paulík zaradil nálezy z Dražoviec, Horných Semeroviec, Mlynáriec, Tekovského Hrádku, z lokality „,b“ v Topol’čanoch a niekol’ko hrobov z pohrebiska karpatskej mohylovej kultúry v Salke.

Ihlica z Dražoviec (obr. 1) pochádza z lokality „b“, tzn., že nedatuje misu z lokality „a“. Bronzy z narušených hrobov v Horných Semerovciach sú charakteristické pre strednú dobu bronzovú (obr. 2). Nepublikované hroby z Mlynáriec patria podla J. Říhovského, ktorý ich poznal z autopsie, staršej fáze velatickej kultúry západného charakteru na území čakanskej kultúry. Hrob 85 zo Salky I je datovaný srdcovitými záveskami do strednej fázy mohylovej kultúry. Oproti tomu je šálka čakanskej kultúry v hrobe 66 zo Salky I cudzím prvkom v inventári karpatskej mohylovej kultúry. S podobným javom sa stretávame v jame 1 velatickej kultúry v Suchej nad Parnou, v ktorom sa vyskytol iný typ čakanskej šálky spolu s amforou karpatskej mohylovej kultúry. Nálezový kontext džbánku z Tekovského Hrádku nie je známy. Džbánok tohto typu sa vyskytol na čakanskom sídlisku v Ipel'skom Sokolci.

Amforku z neistého hrobu na lokalite „b“ v Topol'čanoch republikoval E. Wiedermann v roku 1985 ako amforku lengyelskej kultúry. Ihlica z lokality „a" sa našla mimo sídliska, tzn., že tak ako v Dražovciach a Horných Semerovciach, aj v Topol'čanoch nemá datovanie predčakanského horizontu na prechod stupňov C/D oporu v bronzovej industrii.

Na sídlisku v Topol’čanoch sa odkrylo sedem jám (2-8) a pät chát (2-6). Výber keramiky bol uverejnený na dvoch miestach, jednotlivé nádoby však nie sú vždy spol’ahlivo identifikovatelné. Typy keramiky predčakanského horizontu (obr. 3) pochádzajú zo štyroch chát a troch jám. Pred posúdením ich kultúrnej príslušnosti je potrebné upozornit na to, že J. Ř́hovský už v roku 1963 poukázal na niektoré tvary nádob, resp. prvky v náplni čakanskej kultúry, ktoré sa blížia velatickej kultúre na južnej Morave a v Dolnom Rakúsku, na amfory s lievikovitým hrdlom, misy s vtiahnutým okrajom, strechovite hranené uchá, vyčnievajúce nad okraj nádob, šikmé a vodorovné hranenie pliec nádob, lalokovité výčnelky na okraji nádob a duté nôžky. Vnútorné hranenie okraja amforovitých nádob sa podla J. Říhovského začína vyskytovat’ až v stupni Blučina-Kopčany. V súčasnosti sa pre tento stupeň používa termín stupeň Blučina.

$\mathrm{V}$ typologickej tabul'ke predčakanskej keramiky bolo zohl'adnených pät nádob z jamy 8 . Amfory reprezentuje variant s lievikovitým hrdlom a výčnelkami na vydutí (obr. 3: 15). Tento typ nádob sa vo variabilnej podobe vyskytol aj v jame 6 a v chatách 3-6, tzn. v polovici nálezových celkov. V jame 8 sú zastúpené viaceré varianty amfor. $Z$ nich je z chronologického hladiska najdôležitejšia amfora s etážovitým hrdlom. Nádoby s takto stvárneným hrdlom sa podla J. Ř́hovského na južnej Morave, v Dolnom Rakúsku, v Burgenlande, na juhozápadnom Slovensku a v severozápadnom Mad’arsku objavujú až v stupni HA. Datovaniu jamy 8 zodpovedá šálka s vysoko vytiahnutým uškom (obr. 4: 23), ktorá je nielen v jame I/57 v Sládečkovciach, ale aj v hroboch z Očkova, Großhöfleinu a Gemeinlebarnu datovaná ihlicou s kyjovitou hlavicou. Výskyt tohto typu šálok však nie je obmedzený na tento stupeň. Misa s výrazne prehnutým okrajom (obr. 3: 10) reprezentuje tzv. „čakanské misy“ J. Paulíka. Misa s lalokovitým okrajom (obr. 3: 3) nadväzuje na charakteristický typ mís stredodunajskej mohylovej kultúry. Varianty tohto typu mís sa však vyskytujú aj v stredodunajskej kultúre popolnicových polí. Výskyt v stredodunajskej kultúre popolnicových polí platí aj v prípade misy s vodorovným,

1 Salka I. 
dovnútra rozšíreným ústím, ktorá nadväzuje na mad’arovské misy typu D 4 podla A. Točíka (obr. 3: 2). Duté nôžky (obr. 3: 16) sa vyskytujú aj na keramike čakanskej kultúry, napr. v Čake a Marcelovej.

Džbány s ostro lomenou spodnou častou z chát 2 a 4 (obr. 3: 5, 6), podla doplňujúceho výberu keramiky z roku 1999 aj z chaty 5 , nadväzujú síce na tvary stredodunajskej mohylovej kultúry, ale analogické tvary sa vyskytli na sídliskách čakanskej kultúry v Dedinke a v Ipel’skom Sokolci, ako aj na sídlisku velatickej kultúry v Senci. Štíhly džbán, malú šálku a dutú nôžku z chaty 4 (obr. 3: 4, 8, 14) datujú amfory s vnútorným hranením ústia a typická misa čakanskej kultúry. Kónická šálka z jamy 4 (obr. 3: 11) sa v rámci strednej a neskorej doby bronzovej nedá presnejšie datovat. Vysoká šálka so šikmo žliabkovanou hornou častou vydutia z tej istej jamy (obr. 4: 12) má približnú analógiu v Blučine. V lužickej kultúre je tento typ nádob datovaný do stupňa IV (HA1) podla L. Veliačika. Nálezový kontext šálky s prehnutým hrdlom (obr. 4: 7), ktorá reprezentuje šálky typu Blučina, nie je jasný a pravdepodobne pochádza z chaty 5. Malú kónickú misku z chaty 6 (obr. 3: 9) datujú sprievodné nálezy do stupňa HA1. Nádoba s dvojitou plastickou páskou na vydutí z jamy 6 (obr. 3: 13) je v mohyle z Isztimér-Csőszpuszta datovaná nožom typu Baierdorf. Tým sú datované aj šálky so šikmým žliabkovaním z chaty 4 a jamy 6 do tohto obdobia.

Z krátkeho prehl'adu typov „predčakanskej“ keramiky zo sídliska v Topol'čanoch vyplýva, že ide o sídlisko stupňov BD/HA1 s výrazným podielom keramiky velatickej kultúry.

Napokon sa treba zmienit o typoch nádob, ktoré majú reprezentovat’ predčakanský horizont v porovnaní s čakanskou kultúrou a kultúrou Vál I (Paulík 1963, obr. 40). Misa s lalokovitým okrajom z Topol’čian (E13) už bola spomenutá. Amforu z Bešeňova (F16) iní autori klasifikovali ako amforu kultúry stredodunajských popolnicových polí, resp. staršej fázy velatickej kultúry. Zohl’adnenie dvojkónickej nádoby zo Sládečkoviec (G19) súvisí s datovaním z roku 1960, ktoré v roku 1963 už nebolo platné. Typ mís s jazykovitými výčnelkami na ústí (H22) nemusí byt predchodcom čakanských mís, ked’že sa vyskytuje aj v pilinskej kultúre.

Spoločný výskyt keramiky „predčakanského horizontu“ a čakanskej kultúry v Horných Lefantovciach, Pol’nom Kesove a Topol'čanoch zodpovedá situácii v oblasti rozšírenia stredodunajskej mohylovej kultúry a velatickej kultúry - na pohrebisku v Zohore a na sídliskách v Suchej nad Parnou a Strachotíne. Hrob 7 zo Zohora, ktorý obsahoval o. i. džbán a šálku stredodunajskej mohylovej kultúry, bol zaradený do stupňa Blučina-Kopčany, resp. do stupňa Strachotín-Velké Hostěrádky a do staršieho obdobia stredodunajskej kultúry popolnicových polí. Jama 1 zo Suchej nad Parnou je napriek prvkom mohylovej kultúry datovaná do druhého stupňa velatickej kultúry. Čiastočne paralelnú existenciu stredodunajskej mohylovej kultúry a velatickej kultúry presvedčivo dokazujú dve jamy na sídlisku v Strachotíne. V prípade velatickej kultúry sa teda používalo a dodnes používa datovanie nálezových komplexov podla "mladších" prvkov, kým J. Paulík sa v prípade čakanskej kultúry rozhodol pre opačný postup. Datovanie podla „starších" prvkov však v čakanskej kultúre nemá všeobecnú platnost'. Jama kultúry zo Saroviec, ktorá obsahovala amforu karpatskej mohylovej kultúry, bola zaradená do čakanskej kultúry.

Výskyt keramiky mohylovej kultúry v čakanskej jame v Šarovciach, vo velatickej jame v Suchej nad Parnou spolu s nádobou čakanskej kultúry a v nálezových celkoch s kultúrne „zmiešaným“ inventárom v zozname čakanskej kultúry z roku 1963, ako aj pravdepodobný výskyt šálky čakanskej kultúry v hrobe 66 karpatskej mohylovej kultúry v Salke I, naznačuje prinajmenšom čiastočnú paralelnú existenciu najmladšej fázy karpatskej mohylovej kultúry a čakanskej kultúry. Tak je to aj na Morave v prípade stredodunajskej mohylovej kultúry a kultúry stredodunajských popolnicových polí (stupne Strachotín-Velké Hostěrádky a Blučina).

Z uvedeného vyplýva, že existencia predčakanského horizontu na juhozápadnom Slovensku sa na podklade nálezov, ktoré boli uverejnené v roku 1963, nedá potvrdit’. J. Paulík si bol vedomý problémov, ktoré vyplývali z výskytu tých istých typov keramiky v čakanskej a velatickej kultúre. Názor o vzniku „karpatskej velatickej kultúry“ z čakanskej kultúry ho však prinútil k negovaniu prítomnosti velatickej kultúry na území čakanskej kultúry. Otázka vzniku, resp. pôvodu čakanskej kultúry a jej náplne sa z tohto dôvodu dá riešit až po publikovaní nálezových fondov, ich nepredpojatom vyhodnotení a ich porovnaní so situáciou v Dolnom Rakúsku a na Morave na jednej strane a v Zadunajsku, Burgenlande na druhej strane.

Obr. 1. Dražovce. 1 - bronzová ihlica z lokality „, b“; 2 - nádoba z lokality „a“ (podla Paulík 1960). Mierka: a - 1; b - 2.

Obr. 2. Horné Semerovce. Bronzové predmety z rozrušených žiarových hrobov (podl’a Paulík 1963).

Obr. 3. Topolčany, štadión. 1 - bronzová ihlica, ojedinelý nález; 2-16 - výber keramiky zo sídliska (bez mierky; podla Paulík 1963).

Obr. 4. Topol'čany, štadión. Výber keramiky z jamy 8 (podla Točík/Paulík 1960 a Paulík 1960). Bez mierky.

\author{
Dr. Zoja Benkovsky \\ Donaustr. 89/5 \\ A - 2344 Maria Enzersdorf-Südstadt \\ zoja.benkovsky@gmail.com
}

